\title{
Continuous Body Temperature Monitoring to Improve the Diagnosis of Female Infertility
}

\section{Forlaufende Kontrolle der Körpertemperatur zur Verbesserung der Diagnostik bei weiblicher Infertilität}

\section{(ㄷ) (i) (우)}

Authors

Maren Goeckenjan, Esther Schiwek, Pauline Wimberger

Affiliation

TU Dresden, Department for Gynecology and Obstetrics, Dresden, Germany

Key words

fertility awareness, vaginal biosensor, luteal phase deficiency, polycystic ovary syndrome, infertility

Schlüsselwörter

Fertility Awareness, vaginaler Biosensor, Lutealinsuffizienz, polyzystisches Ovarialsyndrom, Infertilität

$\begin{array}{ll}\text { received } & 5.2 .2020 \\ \text { revised } & 28.4 .2020 \\ \text { accepted } & 1.6 .2020\end{array}$

Bibliography

DOI https://doi.org/10.1055/a-1191-7888

Geburtsh Frauenheilk 2020; 80: 702-712 @ Georg Thieme

Verlag KG Stuttgart · New York | ISSN 0016-5751

Correspondence

Dr. med. Maren Goeckenjan

Klinik und Poliklinik für Frauenheilkunde und Geburtshilfe,

Universitätsklinik der TU Dresden

Fetscherstraße 74, 01307 Dresden, Germany

maren.goeckenjan@uniklinikum-dresden.de

\section{ABSTRACT}

Introduction Ovulatory dysfunction is a major cause of female infertility. We evaluated the use of continuous body temperature monitoring with a vaginal biosensor to improve standard diagnostic procedures for determining ovulatory dysfunction.

Material and Methods This prospective interventional study was performed in a reproductive medicine department of a university hospital. The menstrual cycles of 51 women with infertility were monitored and analysed using three different strategies: sonographic and hormonal assessment (standard approach), continuous core body temperature measurement and analysis using the algorithm of OvulaRing, and lowest daily body temperature measurement monitored with a vaginal biosensor and analysed based on the body temperature curves used in natural family planning.

Results Statistically significant differences were found in the temperature curves of women with luteal phase deficiency and polycystic ovary syndrome compared to women with normal menstrual cycles. The analysis of individual cyclofertilograms can be used to detect cycle phases and estimate the date of ovulation.

Conclusions Continuous body temperature monitoring with a vaginal biosensor can improve the standard diagnostic procedures used to determine ovulatory dysfunction, especially if dysfunction is due to luteal phase deficiency and polycystic ovary syndrome. Analysis of the lowest daily body temperature combined with the basal body temperature measurements used in fertility awareness methods may be equieffective to continuous body temperature measurements with OvulaRing. The results of this study show that a revised diagnostic approach using fewer hormonal assessments combined with continuous body temperature monitoring can reduce the number of appointments in an infertility clinic as well as the costs.

\section{ZUSAMMENFASSUNG}

Einleitung Ovulatorische Dysfunktion ist eine der Hauptursachen der weiblichen Unfruchtbarkeit. Wir haben den Einsatz eines Biosensors zur fortlaufenden Körpertemperaturmessung ausgewertet mit dem Ziel, die Standarddiagnoseverfahren zur Bestimmung der ovulatorischen Dysfunktion zu verbessern.

Material und Methoden Diese prospektive Interventionsstudie wurde in einer Abteilung für Reproduktionsmedizin eines Universitätsklinikums durchgeführt. Die Menstruationszyklen von 51 Frauen mit Infertilität wurden überwacht und analysiert. Dafür dienten 3 verschiedene Strategien: sonografische und hormonelle Untersuchungen (Standardverfahren), die fortlaufende Messung und Analyse der Kernkörpertemperatur mithilfe des Algorithmus des OvulaRing sowie die Messung der tiefsten täglichen Körpertemperatur mit einem 
vaginalen Biosensor mit anschließender Auswertung basierend auf den Körpertemperaturkurven, die bei der natürlichen Familienplannung eingesetzt werden.

Ergebnisse Es gab statistisch signifikante Unterschiede in den Körpertemperaturkurven von Frauen mit Lutealphasendefekten bzw. polyzystischem Ovarialsyndrom im Vergleich zu Frauen mit normalen Menstruationszyklen. Zur Bestimmung der Zyklusphasen und Schätzung des Ovulationszeitpunktes wurden die Zykluskurven (Cyclofertilogramm) der individuellen Frauen analysiert.

Schlussfolgerungen Die fortlaufende Körpertemperaturmessung mit einem vaginalen Biosensor kann zur Verbesserung standardisierter Diagnoseverfahren bei der Bestim- mung der ovulatorischen Dysfunktion eingesetzt werden, insbesondere bei der ovulatorischen Dysfunktion infolge eines Lutealphasendefekts bzw. polyzystischen Ovarialsyndroms. Die Analyse der tiefsten täglichen Körpertemperatur in Kombination mit Basaltemperaturmessungen, die bei der natürlichen Familienplannung verwendet werden, kann ebenso effektiv sein wie fortlaufende Körpertemperaturmessungen mit dem OvulaRing. Die Ergebnisse dieser Studie zeigen, dass ein geändertes diagnostisches Verfahren mit weniger Hormonuntersuchungen, aber in Kombination mit einer fortlaufender Überwachung der Körpertemperatur die Anzahl der Termine in der Infertilitätsklinik sowie die Kosten der Untersuchung reduzieren kann.

\section{Introduction}

It is estimated that $29 \%$ of couples in Germany aged between 30 and 40 years do not have children [1]. In developed countries, unwanted childlessness affects about $9 \%$ of all couples, and around half of these couples seek medical help [2]. The German guidelines on the diagnosis and treatment of infertility prior to starting artificial reproductive techniques were published in 2019 [3].

The diagnostic methods currently used to evaluate infertility patients include cycle monitoring with the detection of ovulation and the evaluation of potential anatomical and functional causes of infertility. Tubal dysfunction, implantation disorders caused by submucosal fibroids, uterine malformations and other infertilityrelated diseases such as endometriosis must be excluded.

Ovulation detection is performed as part of individual menstrual cycle monitoring. Repeated blood sampling and transvaginal sonography during the menstrual cycle are often required. However, it can be difficult to find the optimal time to schedule patients to come to the fertility clinic for blood sampling and ultrasound examinations.

Ovulatory dysfunction disorders such as anovulation or oligoovulation are estimated to account for $21 \%$ of female infertility cases [4]. The NICE guidelines recommend using a serum progesterone assay to confirm ovulation in the predicted midluteal phase [5]. The current German guidelines also support this recommendation [3].

The most important endocrine causes of ovulatory dysfunction are:

- Polycystic ovary syndrome (PCOS). This is the most common female endocrine disorder and affects about $7 \%$ of all women of reproductive age [6]. About $85 \%$ of ovulation disorders are related to PCOS [5]. PCOS is a combination of hyperandrogenaemia, ovulatory dysfunction, and sonomorphologically typical ovaries with an abundance ( $>12$, in more recent guidelines $>20$ ) of small antral follicles measuring 2-8 $\mathrm{mm}$ [7]. In our study, we used the classic sonomorphological criteria for polycystic ovaries which correspond to the Rotterdam criteria [8].
- Diminished ovarian reserve (DOR). This cause of infertility is strongly related to age. Having postponed the wish to have a child to a later stage in life, a high percentage of women presenting to infertility centres has a reduced ovarian reserve. Other reasons for the loss of ovarian reserve and response to hormonal stimulation include genetic disorders, gonadotoxic treatment and surgery. Although a diminished ovarian reserve is not directly associated with reduced fertility [9], ovarian reserve must be assessed before planning further treatment, especially artificial reproductive techniques [10].

- Luteal phase deficiency (LPD). This discrete disorder of the menstrual cycle results in a shortened luteal phase ( $<9$ days), spotting, and reduced fertility. The clinical relevance of LPD is critically discussed [11]. There is currently no clinical standard for the diagnosis of LPD. In our study we defined a shortened luteal phase as $<12$ days with a decreased serum progesterone level of $<30 \mathrm{nmol} / \mathrm{l}$ at least 5 days after confirmed ovulation [12].

Other causes of ovulatory dysfunction include thyroid dysfunction and hyperprolactinaemia.

Fertility awareness methods are based on daily basal body temperature measurements to detect the progesterone-induced postovulatory temperature shift. This symptothermal method uses a combination of morning basal body temperature measurements and assessment of the cervical mucus and has been thoroughly investigated in fertile and infertile couples [13,14].

Recently, the use of intravaginal sensors for the continuous measurement of core body temperatures has been proposed for fertility awareness. One vaginal biosensor, developed by VivoSensMedical $\mathrm{GmbH}$, has been used by women since several years to improve their fertility awareness [15]. So far, however, there have been no studies or recommendations on the use of biosensors to diagnose ovulatory disorders.

A prospective interventional study was performed in the department for reproductive medicine of the Technical University of Dresden. The aim of the study was to evaluate the use of continuous core body temperature measurement using an intravaginal biosensor to improve the standard diagnostic procedures used to identify the causes of female infertility. 


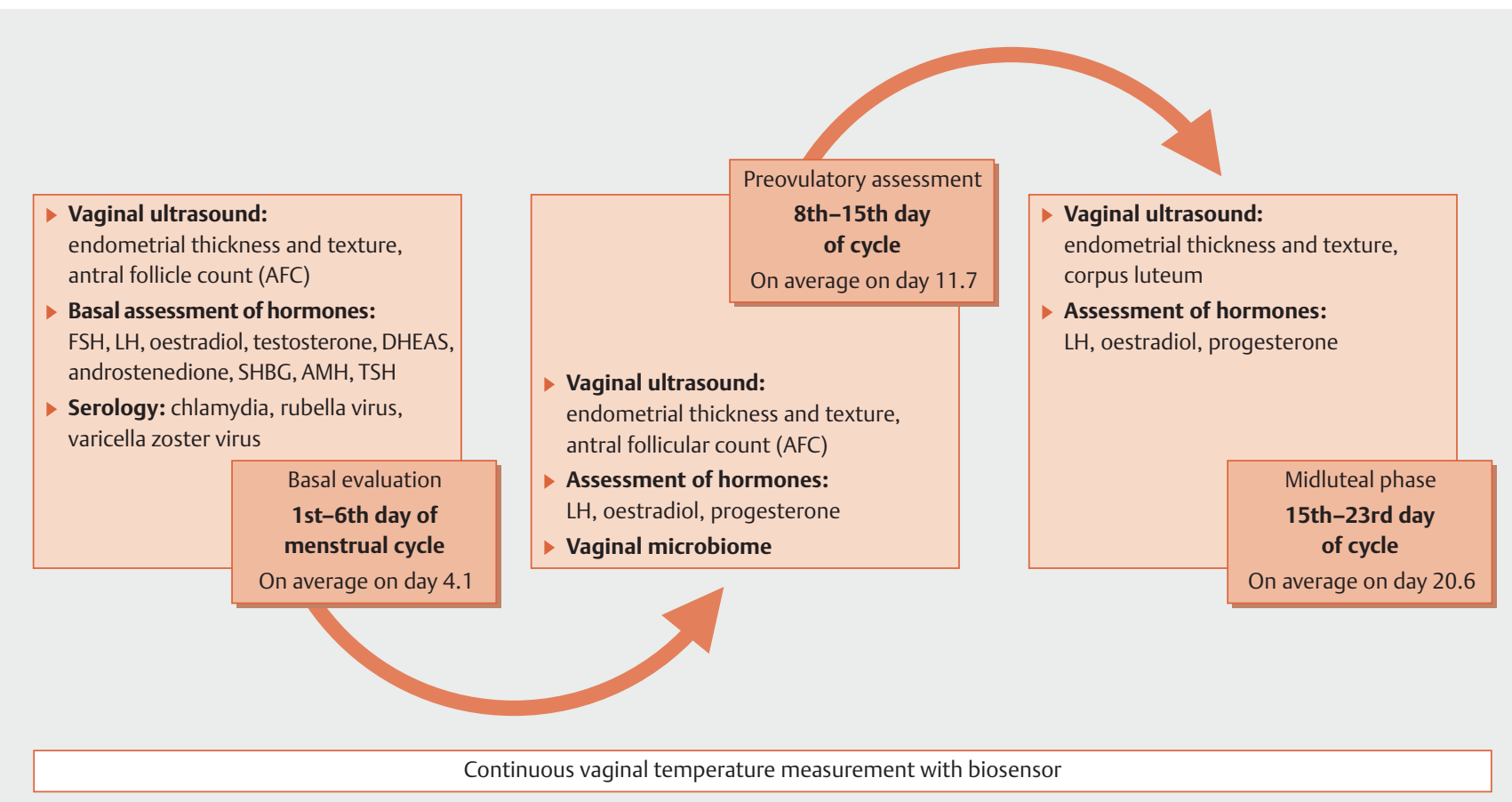

- Fig. 1 Cycle monitoring according to the study protocol.

\section{Material and Methods}

\section{Study design}

This study was designed as a single-centre, prospective, interventional study. Ethical approval was obtained from the local ethics committee (EK270072013). A vaginal biosensor for the continuous measurement of core body temperatures was used in addition to the standard diagnostic procedures for female infertility. All women presenting to the department of reproductive medicine of TU Dresden between October 2013 and March 2014 were asked to take part in the study. All participants gave their informed consent to the study protocol.

\section{Inclusion and exclusion criteria}

Women aged 18-45 years with a diagnosis of infertility were asked to participate in the interventional study. Exclusion criteria were:

- Medication with sexual steroids, hormonal contraceptives or gonadotropin-releasing hormone analogues;

- confirmed, acute genital infection at the time of inclusion;

- known allergic reaction to the materials used in the vaginal biosensor;

- participation in other clinical studies in the past 30 days;

- physical or mental disabilities or other reasons preventing participation in the study (e.g., language barriers).

In the recruitment phase from October 2013 to April 2014, 106 women were initially asked to participate. Forty-seven women could not be included, with reasons for non-inclusion including language barriers $(n=5)$, older age $(n=1)$, refusal to participate $(n=18)$, and other factors $(n=23)$. Of the 59 women who gave their written informed consent, four women decided against using the vaginal sensor after inclusion into the study. Four more women prematurely discontinued their participation for other reasons, including vaginal infection $(n=1)$, intolerance of the biosensor $(n=2)$, and personal reasons $(n=1)$.

Fifty-one women then underwent a standard diagnostic workup with concomitant continuous measurement of core body temperatures using the vaginal biosensor.

\section{Diagnostic evaluation of women with infertility}

Prior to cycle monitoring, both partners were asked about their medical history. During cycle monitoring to assess female fertility, the partner's sperm count was analysed in accordance with the 2010 WHO criteria [16].

Cycle monitoring was performed on at least three defined dates in the cycle and the results were compared with those obtained using standard diagnostic procedures ( $\bullet$ Fig. 1 ). The study protocol provided dates for examinations in the early follicular phase (the 2nd-5th day of the cycle), in the middle of the cycle (preferably on the 12th-14th day of the cycle shortly before ovulation) and in the luteal phase (18th-22nd day of the cycle or seven days after ovulation). Patients with a prolonged cycle were repeatedly seen for further examinations at seven-day intervals. Serum hormones were assessed and ultrasound examinations were performed at each appointment. All participating women were instructed in the use of the biosensor on the first day of cycle monitoring. Women were asked to record their daily activities, sexual intercourse, and special situations in a diary. About half of 


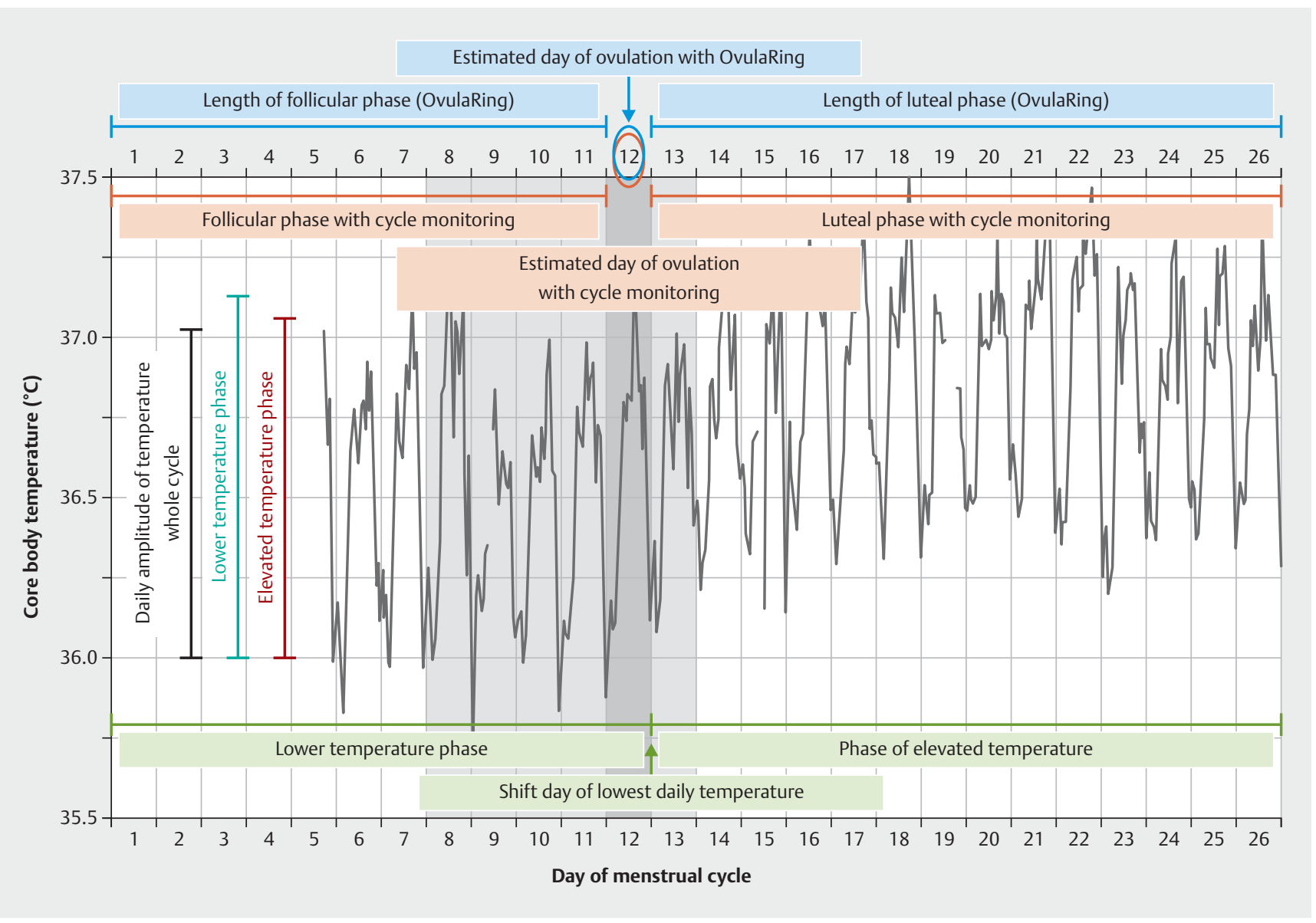

- Fig. 2 Temperature curves obtained with the OvulaRing sensor and analysed using the OvulaRing algorithm, conventional cycle monitoring, and temperature change rules based on the curve for lowest body temperatures.

the women decided to continue using the biosensor for additional no-cost monitoring of their menstrual cycle after the end of the diagnostic cycle and the end of the study period $(n=26)$.

$\mathrm{FSH}$, LH, oestradiol, progesterone, and prolactin were assessed using sandwich immunoassay kits (ADVIA Centaur ${ }^{\circledR}$, Siemens Healthcare Diagnostics, Inc., Tarrytown, NY, USA), and TSH was measured using TSH sandwich immunoassay (Elecsys ${ }^{\circledR}$ TSH kit, Roche Diagnostics GmbH, Germany). Radioimmunoassay used to measure total testosterone (Active ${ }^{\circledR}$ testosterone) and androstenedione, and sex hormone-binding globulin was measured using an SHBG IRMA kit from Beckman Coulter (Galway, Ireland). The radioimmunoassay Immulite ${ }^{\circledR}$ DHEA-SO4 (Siemens Healthcare Diagnostics, Inc., Tarrytown, NY, USA) was used for DHEAS measurement. ELISA kits were used to measure AMH (AMH Gen II ELISA kit, Beckman Coulter, Galway, Ireland) and 17-OH progesterone (IBL INTERNATIONAL GmbH, Hamburg, Germany). Transvaginal ultrasound scanning was performed with GE Healthcare, Voluson 6 and Siemens Sonoline G50.

Three different methods were used to determine typical menstrual cycle parameters:
1. Standard cycle monitoring using hormone testing and ultrasound examinations;

2. Application of body temperature curve rules based on natural family planning (NFP) methods and using the lowest daily temperature obtained from the OvulaRing; and

3. Application of the proprietary algorithm and standardised analysis of OvulaRing.

The NFP temperature curve rules were used as follows [17]:

Three higher values occurring after six consecutive measurements of lower temperatures were considered to indicate a temperature shift. The third value had to be $0.2^{\circ} \mathrm{C}$ higher than the coverline. The coverline connects the highest value of the last six lower temperature values. Two exceptions can occur:

1. A fourth higher value can be used if the third higher measurement is not $0.2^{\circ} \mathrm{C}$ higher than the coverline; this value does not necessarily have to be $0.2^{\circ} \mathrm{C}$ above the coverline.

2. If the second or third elevated measurement is below or on the coverline, this day can be replaced by another elevated value which is $0.2^{\circ} \mathrm{C}$ above the coverline. The exceptions must not be combined.

The temperature curves are shown in > Fig. 2. 


\section{Statistical analysis}

SPSS Statistics (Version 22.0, IBM) was used for statistical analysis. The Kolmogorov-Smirnov test was used to test normality of metric data. A descriptive statistical analysis of variance (ANOVA) was used to test for significance between multiple mean values. Levene's test was used to confirm equality of variances of compared groups prior to analysis with Student's t-test. The correlation coefficient $r$ was used for linear correlations of metric data.

Receiver operating characteristics (ROC) curves were created for each parameter considered significant with t-test, and upper and lower limits with a high sensitivity and specificity were chosen. $\mathrm{P}<0.05$ was considered statistically significant.

\section{Results}

\section{Characteristics of the study population and cohorts}

Fifty-one infertile women with a mean age of $33.3 \pm 4.6$ (24-43) years and a mean body mass index of $23.9 \pm 4.8 \mathrm{~kg} / \mathrm{m}^{2}$ (range: 17.6-40.5) were examined. $68.6 \%$ of the women had primary infertility and $31.4 \%$ had secondary infertility. The mean duration of infertility for all couples was $29.3 \pm 23.6$ months (range: 9-120). A comparison using data from the German IVF registry [18] did not show any significant differences with regard to age (33.3 vs. 35.2 years, $p=0.690$ ) or duration of infertility (2.4 vs. 3.7 years, $\mathrm{p}=0.545)$ at the time of the study.

During the follow-up period of 18 months, 23 observed couples who were still receiving treatment had 19 pregnancies, with a mean time of 6.9 months to pregnancy.

\section{Results of cycle monitoring and continuous body temperature measurement}

Diagnostic cycle monitoring was done in the 51 women in accordance with the study protocol ( $\vee$ Fig. 1). Mid-luteal assessment to confirm ovulation was repeated over eight cycles. 51 women continuously measured their body temperature throughout their menstrual cycle; however, four temperature curves had relevant measurement gaps due to removal of the sensor.

\section{Detection of ovulation}

Ovulation was detected in 47 women using cycle monitoring and elevation of progesterone levels to over $5 \mathrm{nmol} / \mathrm{l}$, confirming the luteal phase. Three women had anovulatory cycles; no ovulation was detected even after prolonged cycle monitoring with repeated controls. In one woman with delayed follicular maturation and, presumably, late ovulation, the luteal control was not repeated. Due to the lack of data, it was not possible to distinguish luteinised unruptured follicle syndrome from luteal insufficiency in this woman.

In four women, the estimated date of ovulation could not be reliably determined with cycle monitoring based on hormone assessment. In five cycles, the total cycle length could not be calculated due to spontaneous pregnancy $(n=2)$ or substitution with natural micronized progesterone $(n=3)$.

There were no significant differences in determining the estimated day of ovulation, follicular phase and luteal phase length between cycle monitoring and continuous temperature measurement $(p=0.267)$ ( $\triangleright$ Table 1$)$. However, there were highly significant differences in the date of temperature shift and the length of low and high temperatures when the rules on the lowest daily body temperature curve were used compared to the OvulaRing algorithm and standard cycle monitoring $(p<0.001)$.

The mean daily amplitudes using the OvulaRing algorithm and curves could be calculated for the entire cycle ( $n=48$, mean: $1.37 \pm 0.14,1.13-1.73^{\circ} \mathrm{C}$ ) as well as the periods of low temperatures ( $n=47$, mean: $\left.1.47 \pm 0.14,1.17-1.73^{\circ} \mathrm{C}\right)$ and high temperatures $\left(n=41\right.$, mean: $\left.1.23 \pm 0.11,1.05-1.41^{\circ} \mathrm{C}\right)$. There was a significant difference between daily amplitudes. The duration of the temperature rise ( $n=42$, mean: $2.76 \pm 1.38,1-6$ days) and the difference in temperature $(n=41$, mean: $0.47 \pm 0.10,0.26-$ $0.69^{\circ} \mathrm{C}$ ) were determined. Missing values were due to gaps in measurement, progesterone substitution, febrile infections, and pregnancies.

\section{Luteal phase deficiency (LPD)}

Serum progesterone levels could be evaluated in 42 women, luteal phase length was confirmed in 40 patients, and both parameters were determined in 38 women. Short luteal phase was de-

- Table 1 Detection of ovulation by hormonal assessment, OvulaRing algorithm for continuous body temperature curves, and analysis of the lowest body temperature curve using selected rules on temperature changes.

\begin{tabular}{|c|c|c|c|}
\hline Method & Estimated ovulation day & $\begin{array}{l}\text { Follicular phase }=\text { days } \\
\text { before temperature shift }\end{array}$ & $\begin{array}{l}\text { Luteal phase }=\text { days after } \\
\text { day of temperature shift }\end{array}$ \\
\hline Hormonal cycle monitoring & $\begin{array}{l}\mathrm{n}=44 \text { : } \\
\text { On cycle day } 14.18 \pm 3.84 \\
\text { (day } 10-31 \text { ) }\end{array}$ & $\begin{array}{l}\mathrm{n}=45: \\
\text { Mean duration: } \\
13.38 \pm 3.9(9-30 \text { days })\end{array}$ & $\begin{array}{l}\mathrm{n}=40: \\
\text { Mean duration: } \\
13.05 \pm 1.58(10-18 \text { days })\end{array}$ \\
\hline OvulaRing algorithm & $\begin{array}{l}\mathrm{n}=42: \\
\text { On cycle day } 15.31 \pm 4.94 \\
\text { (day } 8-34 \text { ) }\end{array}$ & $\begin{array}{l}n=42: \\
\text { Mean duration: } \\
14.31 \pm 4.94 \text { ( } 7-33 \text { days })\end{array}$ & $\begin{array}{l}\mathrm{n}=40: \\
\text { Mean duration: } \\
12.85 \pm 1.69(10-16 \text { days })\end{array}$ \\
\hline $\begin{array}{l}\text { Application of a subset of NFP } \\
\text { rules to interpret lowest body } \\
\text { temperature curves }\end{array}$ & $\begin{array}{l}\mathrm{n}=43 \text { : } \\
\text { Temperature shift occurred } \\
\text { on cycle day } 17.19 \pm 4.8 \\
\text { (day } 12-36 \text { ) }\end{array}$ & $\begin{array}{l}\mathrm{n}=45: \\
\text { Mean duration: } \\
16.67 \pm 5.22(11-35 \text { days })\end{array}$ & $\begin{array}{l}\mathrm{n}=41 \text { : } \\
\text { Mean duration: } \\
11.76 \pm 1.96(8-17 \text { days })\end{array}$ \\
\hline
\end{tabular}



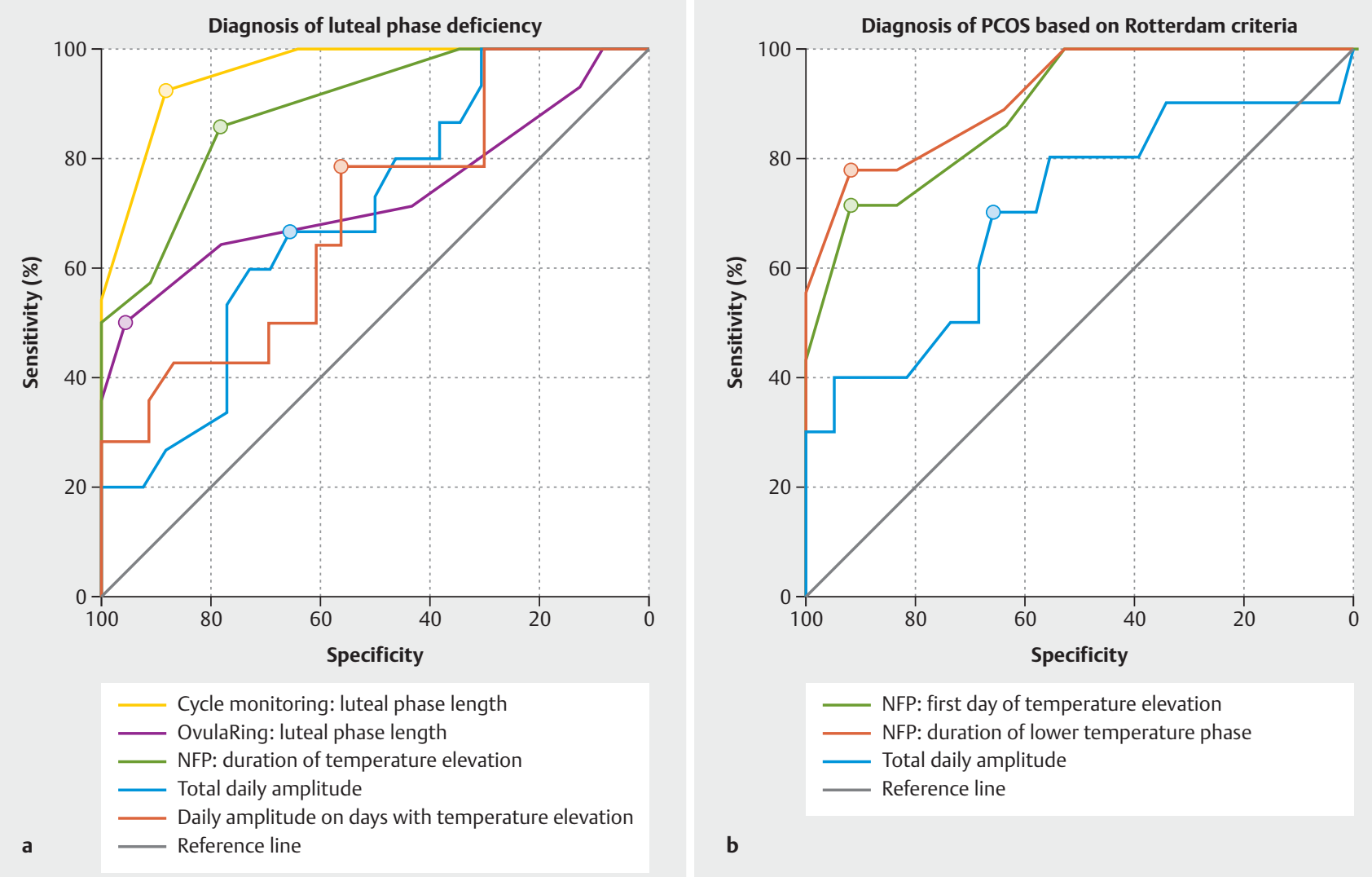

NFP: first day of temperature elevation

NFP: duration of lower temperature phase

Total daily amplitude

Reference line

b

- Fig. 3 a ROC curve of significant parameters for diagnosing LPD using cycle monitoring; b ROC curve of significant diagnostic parameters for diagnosing PCOS based on the Rotterdam criteria. NFP = use of selected rules on temperature changes which are used to analyse lowest daily body temperature curves.

tected in seven women, low progesterone levels in nine, and both values were abnormal in three women. The temperature curves of women with signs of LPD showed statistically significant differences compared to the group of women with normal luteal phase function:

- shorter period of elevated temperatures according to lowest daily body temperature analysis based on selected rules for temperature changes, $\mathrm{p}<0.001$;

- shorter luteal phase as confirmed by the OvulaRing curve, $\mathrm{p}=0.012$;

- higher total daily amplitudes over the whole cycle (OvulaRing), $\mathrm{p}=0.021$;

- higher amplitude in the luteal phase with elevated temperatures (OvulaRing), $\mathrm{p}=0.038$.

\section{Polycystic ovary syndrome (PCOS)}

Hyperandrogenaemia was detected in 14 women who had an elevated FAI (ratio of total testosterone/SHBG $\times 100$, upper normal value for females 3.5). Ovaries showing typical signs of PCOS were confirmed in 20 women, and oligo-/anovulation in five women [8]. Using the Rotterdam criteria, PCOS was confirmed in 10 women, of whom three showed all criteria, one had hyperandrogenaemia and oligo-/anovulation, five had hyperandrogenaemia and polycystic ovaries, and one had both polycystic ovaries and oligo-/anovulation.

The temperature curves of women with positive Rotterdam criteria were compared with those of women with normal values.

No significant differences could be detected for the correlation of hyperandrogenaemia ( $n=14)$ with duration of follicular phase/ duration of lower temperature phase $(p=0.06)$.

The temperature curves after oligo-/anovulation could not be reliably analysed in this subgroup because of the small number of cases $(n=5)$.

However, women with PCOS-typical ovarian sonomorphology ( $n=20)$ had a significantly

- longer total menstrual cycle $(p=0.007)$, follicular phase (OvulaRing; $p=0.022$ ) and lower temperature phase based on the analysis of lowest daily body temperatures using selected rules on temperature changes $(p=0.01)$;

- later ovulation date based on OvulaRing analysis $(p=0.022)$ and a later temperature shift according to NFP methods of temperature analysis $(\mathrm{p}=0.009)$.

The temperature curves of women diagnosed with PCOS based on the Rotterdam criteria also showed significant differences compared to the other women in the study. Women with PCOS had: 

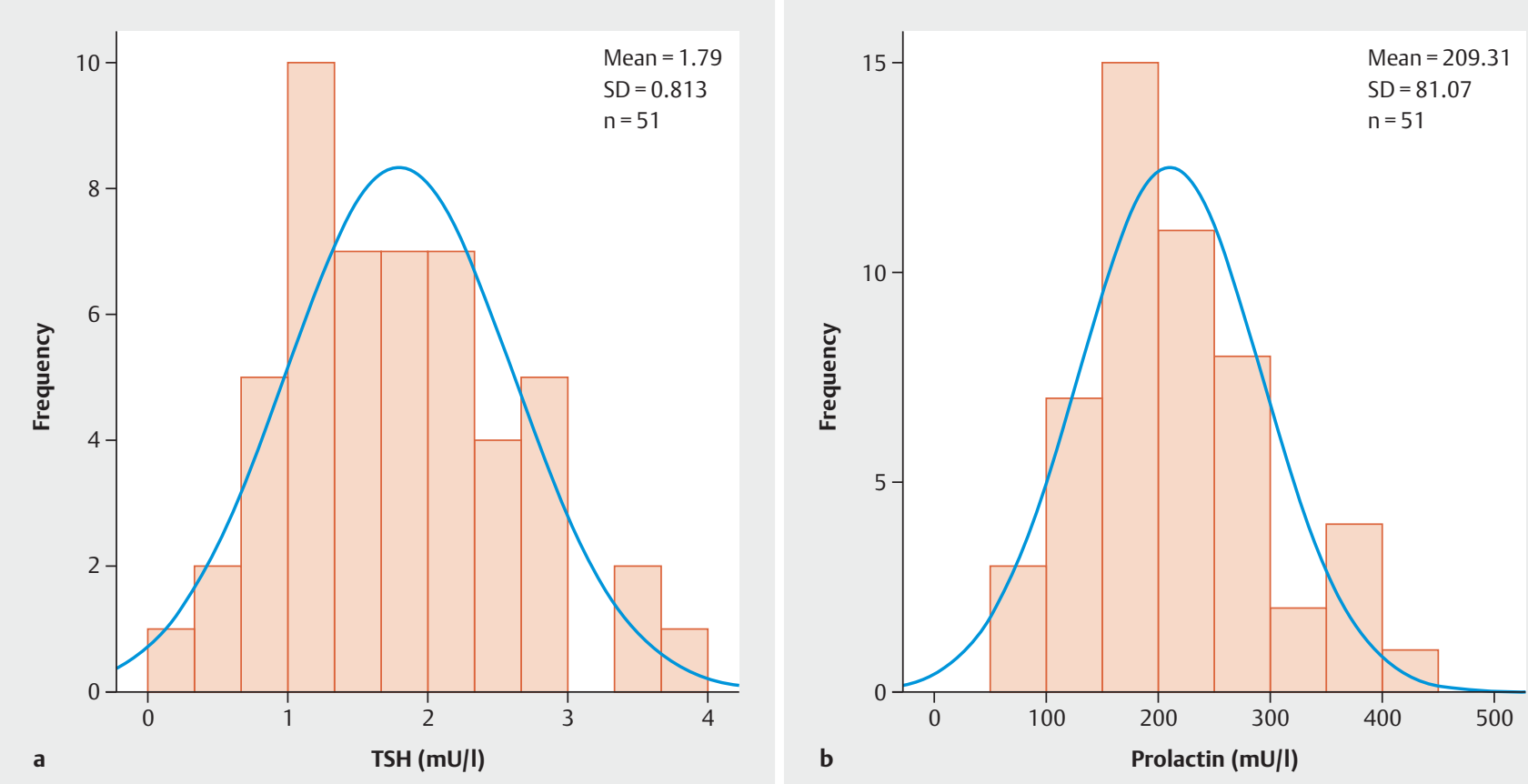

- Fig. 4 Normally distributed TSH (a) and prolactin (b) levels.

- a longer lower temperature phase based on the analysis of lowest daily body temperatures using selected rules on temperature changes ( $p=0.004)$;

- a later temperature shift based on the analysis of lowest daily body temperatures using selected rules on temperature changes $(p=0.03)$;

- higher total daily amplitudes based on the data collected with the OvulaRing $(p=0.014)$.

Diagnostic quality of continuous body temperature curves analysed using OvulaRing and selected rules on temperature changes occurring in lowest daily body temperature curves

The ROC curve for the diagnostic criteria of luteal phase deficiency using the OvulaRing algorithm and selected rules on temperature changes in lowest daily body temperature curves are shown in - Fig. 3a. For the diagnosis of PCOS with Rotterdam criteria, ROC curves were used to determine diagnostic limits with appropriate levels of sensitivity and specificity ( $\bullet$ Fig. $\mathbf{3}$ b).

\section{Thyroid dysfunction and hyperprolactinaemia}

To evaluate thyroid function, TSH (thyroid-stimulating hormone) levels were assessed in all 51 study participants at the time of continuous temperature monitoring. Mean values were $1.8 \pm 0.8 \mathrm{mU} / \mathrm{l}$ (range: 0.14-3.92). In 12 women, levels were controlled through substitution with L-thyroxine. Treatment with L-thyroxine was initiated prior to the diagnostic work-up. Nine women had values of more than $2.5 \mathrm{mU} / \mathrm{l}$. A comparison of the temperature curves of women with elevated TSH $>2.5 \mathrm{mU} / \mathrm{l}$ with those of women with $\mathrm{TSH}<2.5 \mathrm{mU} / \mathrm{l}$ showed no significant differences. The normal distribution of TSH values is shown in $>$ Fig. 4 a.
Serum prolactin was also evaluated in all 51 women. The mean value was $209.3 \pm 81.1 \mathrm{mU} / \mathrm{l}$ (range: $80-402$ ), and all values were within the normal range of 59-619 mU/I. No differences in temperature curves were found which correlated with prolactin levels. The nearly normal distribution of prolactin levels is shown in > Fig. 4 b.

\section{Diminished ovarian reserve (DOR)}

The diagnosis of diminished ovarian reserve was based on the following diagnostic parameters: $\mathrm{AMH}(<1.0 \mathrm{ng} / \mathrm{ml})$, antral follicle count $(<7 /$ ovary), follicular phase length $(<12$ days) or cycle length ( $<25$ days), increased basal FSH $(>8.0 \mathrm{U} / \mathrm{l})$ and basal oestradiol $(<50.0 \mathrm{pg} / \mathrm{ml})$, or normal basal FSH but increased basal oestradiol $(>80.0 \mathrm{pg} / \mathrm{ml}$ ) as signs of early follicular recruitment. Nine women were diagnosed with diminished ovarian reserve. These women had a higher mean age ( $35.7 \pm 4.9$ years) compared to a mean of $32.8 \pm 4.4$ years in women with normal ovarian reserve $(p=0.090)$. A shorter follicular phase, earlier ovulation, shorter low temperature period, and earlier temperature shift were noted, but the differences did not reach statistical significance.

\section{Discussion}

Traditional cycle monitoring prior to infertility treatment with repeated hormone assessments and vaginal ultrasound examinations on three or more days during a single menstrual cycle is associated with a high expenditure of time for patients and higher costs. Since each menstrual cycle may differ inter- and intra-personally, some of these examinations may be without benefit and may therefore have to be repeated. Continuous core body temper- 
ature measurement could improve or even replace the traditional diagnostic procedures used to analyse menstrual cycles prior to infertility treatment. This study analysed the possible benefits and costs of concomitant continuous temperature measurement with a vaginal biosensor for the diagnosis of female infertility caused by ovulatory dysfunction.

\section{Detection of ovulation and duration of follicular phase}

In our study, both continuous temperature measurement and traditional cycle monitoring were successful in detecting ovulation. Differentiating between oligo- and anovulation was sometimes difficult using only conventional cycle monitoring or the OvulaRing algorithm. After the detection of ovulation with conventional cycle monitoring, three women were treated with vaginal progesterone. These cycles were therefore excluded.

In four women, conventional cycle monitoring was not able to successfully determine the date of ovulation. Reasons for this were difficulties in scheduling appointments at the right time $(n=3)$ and, in the case of one woman, discontinuation of monitoring because of a longer cycle length.

In seven women, continuous temperature monitoring did not result in the determination of the date of ovulation. The reasons in these cases were more complex:

- measurement gaps due to ring removal $(n=4)$;

- false detection of ovulation because elevations in temperature were very brief $(n=2)$;

- feverish infection during the periovulatory period $(n=1)$.

Using the selected NFP rules on temperature changes to determine the shift in lowest daily body temperature, it was always possible to differentiate between monophasic and biphasic cycles, provided that the evaluation was not skewed by measurement gaps, fever, or progesterone substitution.

The day of ovulation could be determined in 44/47 women (93.6\%) using conventional cycle monitoring and in 42/47 women (89.4\%) using the continuous temperature measurement algorithm. This difference was not significant. When cycle monitoring was combined with continuous temperature measurement, ovulation date and oligo- or anovulation could be determined in all women with ovulation (100\%).

\section{Luteal phase deficiency}

Luteal insufficiency is considered to be a symptom of various hormonal disorders that should be primarily diagnosed and treated [11]. Clinical relevance is usually only assumed when luteal insufficiency has been confirmed in several cycles.

The women in our study $(n=15)$ who met the most common diagnostic criteria for luteal insufficiency (shortened luteal phase and/or insufficient progesterone levels at least five days after ovulation) were found to have a significantly shorter luteal phase as measured by OvulaRing, a shorter elevated temperature phase after the temperature shift, and higher daily elevation amplitudes.

A dose-response relationship in the range of 1.6 to $19 \mathrm{nmol} / \mathrm{l}$ $(0.5$ to $6 \mathrm{ng} / \mathrm{ml})$ between progesterone levels and body temperature has been reported in previous studies [19]. The relevant range is therefore below the limit of $30 \mathrm{nmol} / \mathrm{l}$. This explains why the difference between highest and lowest temperatures cannot be used to diagnose luteal insufficiency. In addition, not all temperature parameters which are used to determine follicular phase and ovulation time were significant for a diagnosis of luteal insufficiency. However, the parameters "luteal phase length" and "daily amplitude" (for the total cycle and the elevated temperature phase) appear to be suitable indications for a diagnosis and can facilitate and improve a previous diagnosis based on continuous temperature measurements with the OvulaRing. It is assumed that the effect on temperature amplitudes is mainly caused by the relatively longer follicular phase in relation to the shorter duration of the luteal phase, which influences the average daily amplitude.

Especially with late ovulation, it proved difficult to determine progesterone levels at the optimal time using only cycle monitoring. The time of progesterone determination to estimate the date of ovulation can be planned more precisely and individually in advance, based on cycles previously measured with OvulaRing or fertility awareness methods. Using continuous temperature measurements from a number of cycles to create a cyclofertilogram, the assessment of serum progesterone can be reliably optimised after determining the day of temperature shift. The diagnostic procedures to determine luteal insufficiency can be synchronised with the individual menstrual cycle and reduced to a single assessment. Only if progesterone assessment is timed correctly can luteal insufficiency be diagnosed precisely and reliably.

Treatment of LPD to lengthen the luteal phase is uncomplicated, with luteal phase support frequently administered to women with infertility, even without a confirmed indication, in the form of oral or vaginal progesterone or synthetic progestins. Luteal phase support administered without an indication or medical necessity leads to unnecessary costs and side effects, which can include breast tenderness, fatigue, nausea, and dizziness.

Although the current guidelines recommend assessing progesterone in the luteal phase to confirm ovulation, the clinical relevance of a diagnosis of luteal phase deficiency is debated. If only the variable "short luteal phase" based on temperature monitoring had been used to assess LPD, 6/15 women in our study would not have been diagnosed. The combination of hormonal cycle monitoring with temperature curves obtained using the OvulaRing or other reliable methods was useful to determine the optimal time for progesterone assessment without requiring repeated consultations.

The diagnostic values for LPD determined with ROC curves in our study should be validated in a larger study population. The reduced number of days with elevated temperatures can be used to diagnose luteal insufficiency, although it would not be effective to diagnose LPD in some women. The diagnostic power of the combined parameters could be used in future to diagnose luteal phase deficiency even without measuring serum progesterone levels.

\section{Polycystic ovary syndrome (PCOS)}

PCOS is the most common endocrine disorder in women and its prevalence in the general population is reported to be between 4.8 and $19.9 \%$ [20]. This corresponds to the percentage of women in our study (19.6\%) with a diagnosis of PCOS who met at least two of the three Rotterdam criteria. The prevalence of PCOS in 
women who undergo ART cycles in our centre of reproductive medicine is $16.6 \%$ [21].

In our study, significant differences were seen in the cyclofertilograms of women with PCOS compared to women without PCOS. Analysis of basal body temperature curves showed that the temperature shift occurred significantly later. The daily amplitude of temperature changes measured by the OvulaRing also showed significant differences. However, total cycle length, follicular phase length based on cycle monitoring, and follicular phase length based on analysis using the OvulaRing algorithm did not show significant changes between the groups of women with PCOS and those without. Despite prolonged follicular maturation in women with PCOS, the length of the luteal phase was normal. The significant changes in total daily amplitudes are very likely due to the altered relationship between the longer follicular phase and the normal luteal phase. Because of the longer follicular phase, the higher daily amplitudes during the follicular phase pushes up average amplitude values.

Depending on the combination of Rotterdam criteria, detection rates for PCOS subgroups evaluated with cycle monitoring based on temperature measurements differ. PCOS subgroups with polycystic ovarian morphology in particular showed a stronger correlation with the parameters of the OvulaRing. There was no clear association between hyperandrogenaemia and analysed cycle parameters. The prolonged follicular phase in women with PCOS can be easily determined using temperature curves, even though the criteria of oligo-/anovulation is not met.

The cut-off values for PCOS determined with ROC curves need to be verified in a study with a larger sample size. In a larger study, a diagnostic score could be developed using different valid parameters for continuous temperature measurements. Such a score could combine the three parameters "prolonged duration of follicular phase of more than 19 days", "temperature shift using NFP criteria of $>20$ days", and "mean daily amplitude of more than $1.39^{\circ} \mathrm{C}$ during the total cycle".

We suggest that a continuous temperature curve or BBT curve measured for a period of more than three months could easily be analysed using this algorithm and would facilitate a diagnosis of PCOS. In our clinic, only testosterone and SHBG are usually measured during basal hormone analysis. If PCOS is already suspected preclinically, extended androgen diagnostic procedures with additional measurement of DHEAS, androstenedione, and $17-\mathrm{OH}$ progesterone could be carried out during the first examination.

\section{DOR, thyroid dysfunction, hyperprolactinaemia}

No significant temperature parameters were found for the other three investigated hormonal disorders (diminished ovarian reserve, thyroid dysfunction, and hyperprolactinaemia). In the case of limited ovarian reserve, AMH levels are mainly used for diagnostic purposes. AMH levels decrease long before cycle changes such as shortened follicular phase or total cycle length occur. These changes tended to be not significant in patients with reduced AMH levels.

The TSH levels of patients with thyroid dysfunction were normal or discretely elevated in women with infertility. None of the women had hyperprolactinaemia. Cycle changes with a prolonged cycle duration are theoretically expected in women with signifi- cantly elevated TSH levels and/or clinical hyperprolactinaemia. However, this study should be repeated in a larger group with a higher mean age.

\section{Practical use}

The additional benefit of continuous temperature measurement with a vaginal biosensor for standard diagnostics in women with infertility was shown in this study, especially in the detection of ovulatory disorders. However, the measurement of core body temperature alone cannot replace diagnostic procedures for infertility. Continuous temperature measurement with the vaginal body temperature sensor OvulaRing provides reliable data for determining individual cycle phases and identifying late ovulation. Combining continuous temperature measurement with a reduced form of cycle monitoring could save both costs and time. ( $\vee$ Fig. 5).

Based on the results of our study, we would recommend a single examination carried out at the beginning of the menstrual cycle consisting of standard evaluation of hormone levels, including TSH, prolactin, AMH, FSH, oestradiol, and LH, and vaginal sonography carried out at the same time to exclude anatomical or functional causes of infertility and perform antral follicle counts of both ovaries. After this examination, continuous vaginal temperature measurement can be used to obtain data on the individual menstrual cycle/create a cyclofertilogram. If the luteal phase shows abnormalities suggesting luteal phase deficiency, progesterone levels should be determined at the optimal time which is at least five days after the rise in temperature in the subsequent cycle. If this combination of procedures is used, it would be possible to omit the two additional standard appointment to assess hormone levels and carry out vaginal ultrasound scans in the middle and second half of the cycle while achieving equivalent diagnostic results. Patients would benefit from the reduced number of appointments and the lower cost.

\section{Limitations of the study}

If the standard combined hormonal and sonographic evaluation of fertility is replaced with a vaginal biosensor to measure core body temperature changes during the menstrual cycle, a serious limitation of this approach would the lack of any examination to detect hormonal or anatomical disorders. A comprehensive diagnosis of female infertility can only be obtained if continuous body temperature measurements are combined with an initial appointment consisting of a vaginal ultrasound examination and a standard set of hormonal assessments. Because of the relatively small number of analysed cycles in our study, the values obtained during cycle monitoring and analysed using NFP rules for temperature changes and the OvulaRing algorithm are still only initial results and must be repeated and confirmed in the context of larger studies.

Another limitation of this analysis is the lack of a control group. The use of fertility awareness rules to analyse the lowest daily temperatures obtained from the OvulaRing data served this purpose. The NFP rules on temperature changes were applied, even though they were originally developed for use with basal body temperatures and not with lowest daily temperatures that are not correlated with activity levels or morning waking tempera- 
- Vaginal ultrasound: endometrial texture, AFC, exclusion of ovarian endometriosis

- Basal hormonal assessment:

FSH, LH, oestradiol, testosterone, DHEAS, androstenedione, SHBG, AMH, TSH

- Screening for infections: chlamydia, rubella, varicella zoster virus

2nd-5th day of menstrual cycle

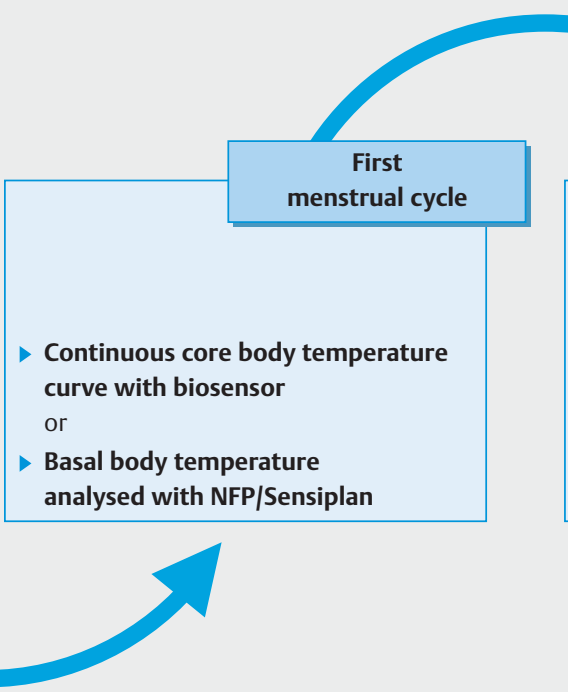

- Suspicious luteal phase

$\rightarrow$ treatment with progesterone

- Suspected PCOS:

intensified androgen assessment, insulin resistance

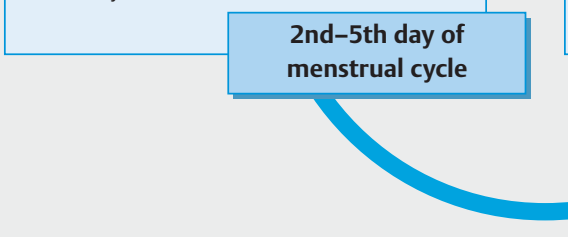

Fig. 5 Proposed diagnostic procedure using basal hormonal and sonographic assessments and temperature measurements to diagnose female infertility.

tures. Another weakness is that the rules on temperature changes were applied even though no data on cervical mucus changes were obtained. In further studies, women who use the NFP method after receiving individual training could serve as a more reliable control group.

Up to now, there are no studies showing that the lowest body temperature recorded by a continuous temperature sensor can be used to calculate fertile days with the same accuracy as the morning waking temperature method. Existing studies only show data for the analysis of continuous temperature curves, with proprietary algorithms used for curves recorded with different vaginal biosensors [15, 22].

We found that the lowest nocturnal temperature can also be reliably determined with other devices. Nevertheless, continuous temperature measurements were useful to determine the investigated parameters "daily temperature amplitude (total, low, and high)", "follicular phase length", "estimated ovulation date", and "luteal phase length".

The cost of the OvulaRing for the routine diagnosis of infertility must be considered. Women with no chance of spontaneous conception will not benefit from a precise evaluation of their fertility window in subsequent menstrual cycles. An alternative to cost-intensive cycle monitoring with the OvulaRing is individual NFP training based on the self-assessment of basal body temperatures and cervical mucus.

Of course, not every woman will wish to wear a vaginal sensor. In this study, 22/106 patients who presented to our fertility centre rejected the use of a vaginal sensor for vaginal temperature monitoring. Four women initially wore the OvulaRing but decided not to continue with the sensor. However, $90 \%$ of the women who decided to use the OvulaRing were very satisfied with the device and welcomed the opportunity to obtain additional information about their menstrual cycle. They confirmed that they would continue to use the OvulaRing.

\section{Conclusions}

This study was designed to interpret the continuous body temperature data of a single diagnostic menstrual cycle and compare the diagnostic value of standard cycle monitoring using hormonal assessment and ultrasound scans with lowest measured body temperatures analysed using selected NFP rules on temperature changes and the analysis of continuous body temperature curves using the algorithm of the OvulaRing sensor. The possible additional value as a diagnostic method for hormonal causes of female infertility was analysed retrospectively. Forecasting the next cycle was not the focus of this study.

We propose a new diagnostic standard consisting of reduced routine screening but with the addition of temperature measurements throughout the diagnostic cycle to determine the causes of female infertility. The use of selected rules on temperature changes to interpret the lowest body temperature curve and the algorithm of a vaginal biosensor such as OvulaRing ${ }^{\circledR}$ could improve standard diagnostic procedures, especially in women with longer and irregular cycles.

\section{Acknowledgements}

We would like to acknowledge the contribution of Henry Alexander in providing the biosensors for study purposes and Denise Wyzisk in supporting the data analysis and concept of the article. 


\section{Conflict of Interest}

The vaginal biosensors (OvulaRing) were provided by the company VivoSensMedical GmbH for the study. The company had no influence on the clinical interpretation of any of the collected data. The authors of the study declare that they have no conflict of interest related to any topics in the study.

\section{References}

[1] Wippermann C. Kinderlose Frauen und Männer - Ungewollte oder gewollte Kinderlosigkeit im Lebenslauf und Nutzung von Unterstützungsangeboten. Bundesministerium für Familie, Senioren, Frauen und Jugend, Hrsg. 1. Aufl. 2014. Online: https://www.bmfsfj.de/blob/94130/ bc0479bf5f54e5d798720b32f9987bf2/kinderlose-frauen-undmaenner-ungewollte-oder-gewollte-kinderlosigkeit-im-lebenslauf-undnutzung-von-unterstuetzungsangeboten-studie-data.pdf; last access: 05.02.2020

[2] Boivin J, Bunting L, Collins JA et al. International estimates of infertility prevalence and treatment-seeking: potential need and demand for infertility medical care. Hum Reprod 2007; 22: 1506-1512. doi:10.1093/ humrep/dem046

[3] Toth B, Baston-Büst DM, Behre HM et al. Diagnosis and Therapy Before Assisted Reproductive Treatments. Guideline of the DGGG, OEGGG and SGGG (S2k Level, AWMF Register Number 015-085, February 2019) Part 1, Basic Assessment of the Woman. Geburtsh Frauenheilk 2019; 79: 1278-1292. doi:10.1055/a-1017-3389

[4] Hull MG, Glazener CM, Kelly NJ et al. Population study of causes, treatment, and outcome of infertility. Br Med J (Clin Res Ed) 1985; 291: 1693-1697

[5] National Collaborating Centre for Women's and Children's Health (UK). Fertility: Assessment and Treatment for People with Fertility Problems. NICE Clinical Guidelines, No. 156. London: Royal College of Obstetricians \& Gynaecologists; 2013. Online: https://www.ncbi.nlm.nih.gov/books/ NBK247932/; last access: 25.10.2019

[6] Azziz R. PCOS: a diagnostic challenge. Reprod Biomed Online 2004; 8: 644-648. doi:10.1016/s1472-6483(10)61644-6

[7] Teede HJ, Misso ML, Costell MF et al.; International PCOS Network. Recommendations from the international evidence-based guideline for the assessment and management of polycystic ovary syndrome. Hum Reprod 2018; 33: 1602-1618. doi:10.1093/humrep/dey256

[8] The Rotterdam ESHRE, ASRM-Sponsored PCOS Consensus Workshop Group. Revised 2003 consensus on diagnostic criteria and long-term health risks related to polycystic ovary syndrome. Fertil Steril 2004; 81: $19-25$
[9] Steiner AZ, Pritchard D, Stanczyk FZ et al. Association between biomarkers of ovarian reserve and infertility among older women of reproductive Age. JAMA 2017; 318: 1367-1376. doi:10.1001/jama.2017.14588

[10] Cohen J, Mounsambote L, Prier P et al. Outcomes of first IVF/ICSI in young women with diminished ovarian reserve. Minerva Ginecol 2017; 69: 315-321. doi:10.23736/S0026-4784.16.04003-X

[11] Practice Committee of the American Society for Reproductive Medicine. Current clinical irrelevance of luteal phase deficiency: a committee opinion. Fertil Steril 2015; 103: e27-e32. doi:10.1016/j.fertnstert.2014. 12.128

[12] Strowitzki T. Praktisches Vorgehen bei gestörter Ovarfunktion und damit assoziierten Phänomenen. In: Leidenberger F, Strowitzki T, Ortmann $\mathrm{O}$, Hrsg. Klinische Endokrinologie für Frauenärzte. Heidelberg: Springer Medizin Verlag; 2009: 635-712

[13] Frank-Herrmann P, Sottong U, Baur S et al. Natürliche Familienplanung: Sensiplan ${ }^{\circledR}$ - eine moderne, verlässliche Methode. Gynäkologe 2011; 44: 17-22. doi:10.1007/s00129-010-2659-5

[14] Frank-Herrmann P, Jacobs C, Jenetzky E et al. Natural conception rates in subfertile couples following fertility awareness training. Arch Gynecol Obstet 2017; 295: 1015-1024. doi:10.1007/s00404-017-4294-z

[15] Regidor P-A, Kaczmarczyk M, Schiweck E et al. Identification and prediction of the fertile window with a new web-based medical device using a vaginal biosensor for measuring the circadian and circamensual core body temperature. Gynecol Endocrinol Off J Int Soc Gynecol Endocrinol 2018; 34: 256-260. doi:10.1080/09513590.2017.1390737

[16] World Health Organization, ed. WHO laboratory Manual for the Examination and Processing of human Semen. 5th ed. Geneva: World Health Organization; 2010

[17] Arbeitsgruppe NFP. Natürlich und sicher - Das Praxisbuch. 20. Aufl. Stuttgart: Trias-Verlag; 2018

[18] Deutsches IVF Register. D.I.R-Jahrbuch 2014. J Reprod Med 2015; 12 : 511-545

[19] Leyendecker G, Hinckers K, Nocke W et al. Hypophysäre Gonadotropine und ovarielle Steroide im Serum während des normalen menstruellen Cyclus und bei Corpus-luteum-Insuffizienz. Arch Gynec Obstet 1975; 218: 47-64

[20] Yildiz BO, Bozdag G, Yapici Z et al. Prevalence, phenotype and cardiometabolic risk of polycystic ovary syndrome under different diagnostic criteria. Hum Reprod Oxf Engl 2012; 27: 3067-3073. doi:10.1093/ humrep/des 232

[21] Fischer D, Reisenbüchler C, Rösner $S$ et al. Avoiding OHSS: Controlled ovarian low-dose stimulation in women with PCOS. Geburtsh Frauenheilk 2016; 76: 718-726

[22] Papaioannou S, Aslam M, Al Wattar BH et al. User's acceptability of OvuSense: A novel vaginal temperature sensor for prediction of the fertile period. J Obstet Gynaecol 2013; 33: 705-709 